\title{
Development of assembled current lead prepared by the TFA-MOD processed YBCO tapes
}

\section{Y 系超伝導テープ線材を用いた集合型電流リードの開発}

Ryosuke MATSUMURA, Haruki MOTOHASHI, Yuto HOSONO and Yutaka YAMADA

Department of Materials Science, Tokai University, 4-1-1 Kitakaname, Hiratuka, Kanagawa, 259-1292

Japan

TEL:+81-463-58-1211 FAX:+81-463-50-2096 e-mail: moet.chandon.0731@ gmail.com

(Received 7 March, $2014 \quad$ Accepted 18 April, 2014)

\begin{abstract}
HTS current lead have been prepared by the TFA-MOD processed YBCO tapes. A current lead unit is composed of 6 bundles stacked by 4 YBCO tapes, $\mathrm{Cu}$ end caps and a pair of stainless steel boards. The YBCO tape is $5 \mathrm{~mm}$ in width and around $130 \mu \mathrm{m}$ in overall thickness. The YBCO superconducting layer with $1.5 \mu \mathrm{m}$ is formed on oxide buffered layers on Hastelloy substrate tape. The critical current of $24 \mathrm{YBCO}$ tapes ranges from $145 \mathrm{~A}$ to $166 \mathrm{~A}$ at $77 \mathrm{~K}$ and self-field. The YBCO current lead is assembled from the 4 current lead units in parallel. The transport current of $10 \mathrm{kA}$ at $77 \mathrm{~K}$ was stably carried with no voltage generation on the YBCO tapes of the assembled current lead for 10 minutes. Rogowski coils were attached on 4 current lead units to evaluate current distribution of them. The current unbalance of $930 \mathrm{~A}$ occurred between 4 units at transport current of $10 \mathrm{kA}$.
\end{abstract}

Keywords : HTS current lead, TFA-MOD process, YBCO tapes, Transport performance, Current distribution

\section{INTRODUCTION}

$\mathrm{Y}_{1} \mathrm{Ba}_{2} \mathrm{Cu}_{3} \mathrm{O}_{7-\mathrm{x}}(\mathrm{YBCO}) 、 \mathrm{Bi}_{2} \mathrm{Sr}_{2} \mathrm{Ca}_{2} \mathrm{Cu}_{3} \mathrm{O}_{10}(\mathrm{Bi} 2223)$ や $\mathrm{Bi}_{2} \mathrm{Sr}_{2} \mathrm{Ca}_{1} \mathrm{Cu}_{2} \mathrm{O}_{8}(\mathrm{Bi} 2212)$ などを代表とする臨界温度 $77 \mathrm{~K}$ 以上を示す酸化物系高温超伝導体(HTS)の応用として電 流リードが考えられる。電流リードとは室温におかれる 電源から極低温下の超伝導機器に電流を供給する導体で ある。一般には $\mathrm{Cu}$ あるいは $\mathrm{Cu}$ 合金が用いられている が、通電時のジュール発熱と室温からの伝導熱により最 適化しても $1.2 \mathrm{~W} / \mathrm{kA}$ の熱侵入量が避けられない。一方、 酸化物系高温超伝導体を用いると電気抵抗が 0 であるた めジュール発熱が無く、熱伝導もセラミックスであるた め低く、大電流・低熱侵入の超伝導電流リードが可能と なる。本研究では、TFA-MOD(Tri Fluoro Acetates-Metal Organic Deposition)法 YBCO 超伝導テープ線材を用いた 2

SAS Award was given to this paper presented as Poster Presentation at the 2013 SAS Intelligent Symposium.
$\mathrm{kA}$ 級電流リードユニット1を作製し、これらを集合させ た集合型電流リード 2 の開発を目的とする。

\section{EXPERIMENTAL}

Figure 1 に TFA-MOD 法 YBCO 線材の外観写真及び断 面模式図を示す。YBCO 線材構造は上から $\mathrm{Ag}$ 安定化保 護層(厚さ: $24 \mu \mathrm{m}) 、 Y B C O$ 超伝導層(厚さ : $1.5 \mu \mathrm{m}$ )、酸 化物中間層(厚さ: $2.2 \mu \mathrm{m}$ )、Hastelloy 基板(厚さ: $100 \mu \mathrm{m}$ ) である。リールに巻かれた長尺線材から幅 $5 \mathrm{~mm}$ の長尺 線材から長さ $280 \mathrm{~mm}$ と、長さ $240 \mathrm{~mm}$ の線材をおのお の 48 本、計 96 本を切り出した。

Figure 2 に液体窒素中・自己磁場下における $\mathrm{YBCO}$ 線 材の素線 Ic 值を示す。 YBCO 線材 96 本の素線 Ic 值は最 大 $166 \mathrm{~A} 、$ 最小 $145 \mathrm{~A} 、$ 平均 $153 \mathrm{~A}$ である。また各電流リ ードュニットの素線 Ic 值の合計は、Unit 1 が 3647 A、 Unit 2 が 3606 A、Unit 3 が 3930 A、Unit 4 が 2980 A である。 
Figure 3 に作製した電流リードユニットの外観及び模 式図を示す。YBCO 線材は上述した長短各 2 本、計 4 本 1 組を重ね合わせ、それらを並列に 3 列等間隔に配置し た後、反対側にも同様に 3 列配置した。表裹側の計 6 列 24 本の YBCO 線材両端を $\mathrm{Cu}$ 電極にハンダ接合し、 $\mathrm{Cu}$ 電極両側にシャントの機能を兼祆備えた補強材として厚 さ $2 \mathrm{~mm}$ のステンレス鋼板 2 枚を挟み込む形でボルト 接続し電流リードニニットを作製した。同様の作製方法 で Unit 1 4の、計 4 組を作製した。

Figure 4 に集合型電流リードの外観及び模式図を示す。 4 組の電流リードユニットの両端を四角形 $\mathrm{Cu}$ 電極の外 周部にボルト接続した。通電試験は液体窒素中・自己磁 場下において行い、直流 4 端子法により各電圧端子間の 発生電圧を測定した。集合型電流リードの電圧測定箇所 は電流リードユニットの発生電圧 : $\mathrm{V}_{\text {Unit }} 、 \mathrm{Cu}$ 電極と

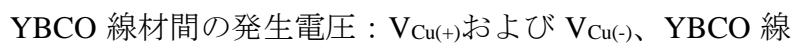
材の発生電圧 : $\mathrm{V}_{\mathrm{YBCO}}($ 電圧端子間距離 : $170 \mathrm{~mm}$ )である。

Figure 5 にロゴスキーコイルの外観及び模式図を示す。 ロゴスキーコイルは直径 $3 \mathrm{~mm}$ 、全長 $100 \mathrm{~mm}$ のシリコン チューブに、直径 $0.084 \mathrm{~mm}$ の $\mathrm{Cu}$ 線材を巻きつけたもの を用いた。形状は周回長 $0.087 \mathrm{~m}$ 、小半径 $0.0015 \mathrm{~m}$ 、巻き 数 3000 である。ロゴスキーコイルの起電力 $\mathrm{e}_{\mathrm{s}}$ の計算は (1)式を用いた。

$$
e_{S}=\frac{\pi r^{2} \mu_{0} N}{l} \frac{d i}{d t}[\mathrm{~V}]
$$

$\mathrm{r}$ :小半径 $[\mathrm{m}] 、 \mu_{0}$ :透磁率 $4 \pi \times 10^{-7}[\mathrm{H} / \mathrm{m}] 、 \mathrm{~N}$ : 巻き数、 1:周回長 [m]

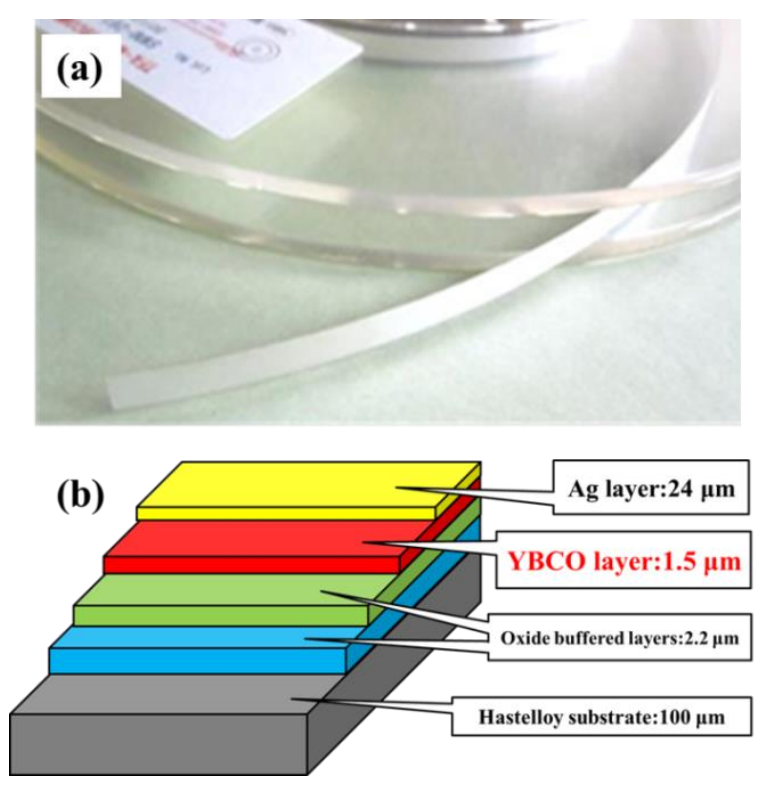

Fig. 1. TFA-MOD processed YBCO tape. (a) Long tape wound on a reel, (b) Schematic cross-section of the tape.
このロゴスキーコイルを各電流リードユニットに取り付 け、(1)式より得られた計算值と通電時の測定值を比較し、 電流スイープ時における集合型電流リード内 4 組の電流 リードュニットの偏流を評価した。

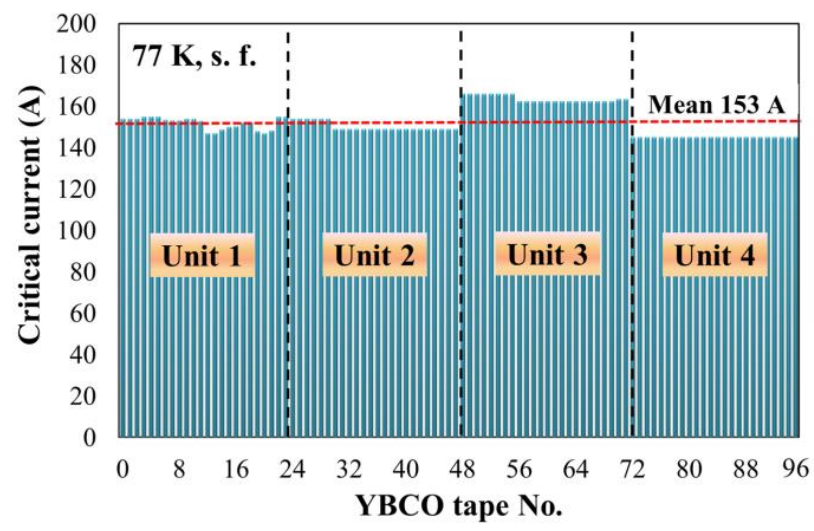

Fig. 2. Transport current of YBCO tapes prepared for the current lead at $77 \mathrm{~K}$ in self-field.
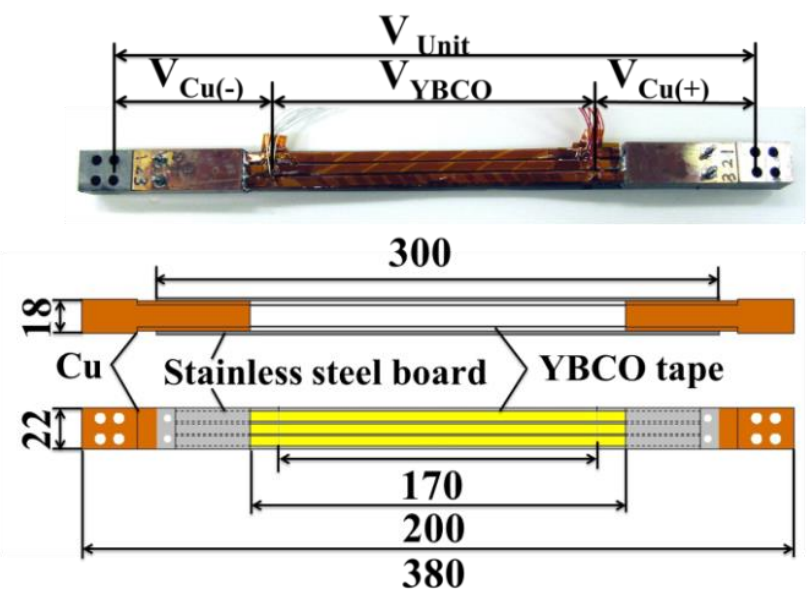

Fig. 3. A current lead unit composed of 24 YBCO tapes, stainless steel boards and $\mathrm{Cu}$ caps at both ends.

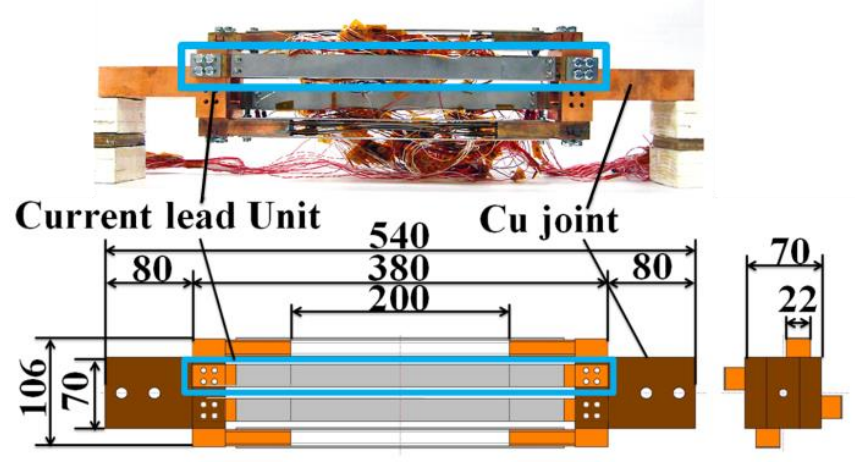

Fig. 4. Current lead assembled from 4 current lead units in parallel. 


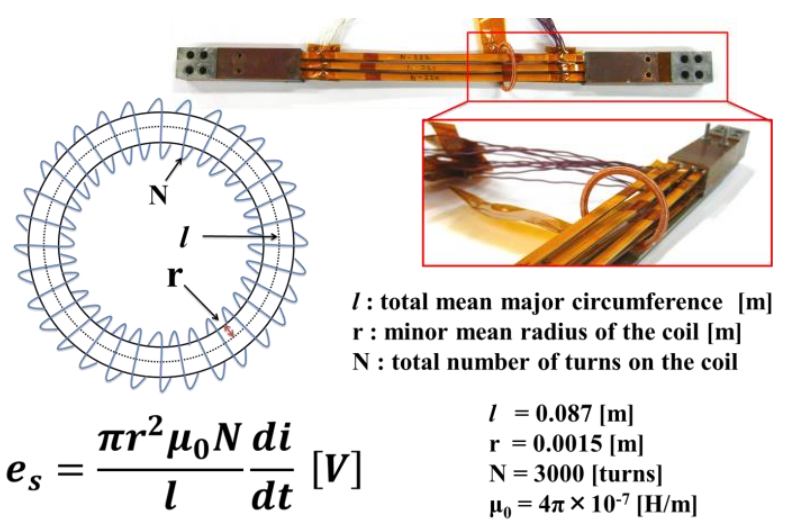

Fig. 5. Rogowski coil attached on each current lead unit.

\section{RESULTS AND DISCUSSION}

集合型電流リードに $10 \mathrm{kA}$ 通電したときの電流 Unit 4 における通電結果を Fig. 6 に示す。Unit 4 の各電圧 $\mathrm{V}_{\mathrm{Cu}(+)}$ 、

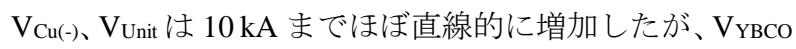
には電圧の発生なく通電ができた。10 kA 通電時の $\mathrm{Cu}$ 電 極部 $\mathrm{V}_{\mathrm{Cu}(+)}$ には $1.2 \mathrm{mV} 、 \mathrm{~V}_{\mathrm{Cu}(-)}$ には $1.1 \mathrm{mV}$ の電圧が発生 し、これらの和は全体電圧 $V_{U n i t}$ の $2.3 \mathrm{mV}$ とほぼ等しく なった。

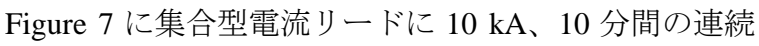
通電結果を示す。一部のユニットの $\mathrm{VYBCO}_{\mathrm{YBCO}}$ 電圧発生が

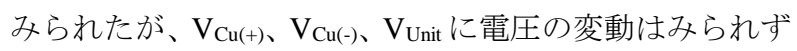
安定した通電が可能であった。

Figure 8 にスイープレート $2500 \mathrm{~A} / \mathrm{s}$ で $10 \mathrm{kA}$ 通電時の 電流の立ち上げ - 保持 - 立ち下げをしたときのロゴスキ ーコイルの起電力を示す。通電開始後約 1.6 秒後 $(4000 \mathrm{~A})$ 近傍の Unit 1 4 の起電力はそれぞれ $181 \mu \mathrm{V} 、 236 \mu \mathrm{V}$ 、 $217 \mu \mathrm{V} 、 218 \mu \mathrm{V}$ であったが、電流の増加と共に各ユニッ 卜間の起電力に差が生じ、4 秒後 $(10 \mathrm{kA})$ 通電時には Unit $1 \sim 4$ にそれぞれ $126 \mu \mathrm{V} 、 260 \mu \mathrm{V} 、 215 \mu \mathrm{V} 、 226 \mu \mathrm{V}$ の起電 力となり、各ユニット間に最大 $134 \mu \mathrm{V}$ の差が生じた。そ の後、10 kA 一定電流通電時にはロゴスキーコイルの起 電力は 0 となり、電流立ち下げ時のロゴスキーコイルに は立ち上げ時とほぼ同様の起電力が生じた。

Figure 9 にロゴスキーコイルの起電力より計算した集 合型電流リード各ユニットに分流した電流值を示す。10 kA まで通電したとき、Unit 1 には 2180 A、Unit 2 には 3170 A、Unit 3 には 2710 A、Unit 4 には2870 A の電流が 流れたものと計算され、電流リードユニットには最大 990 A の偏流が生じたと思われる。この時電流值の合計 值は $10930 \mathrm{~A}$ となるので、実際の通電電流值である 10000 A とは 930 A の差が生じたが、集合型電流リード内の偏 流をある程度定量的に評価出来た。

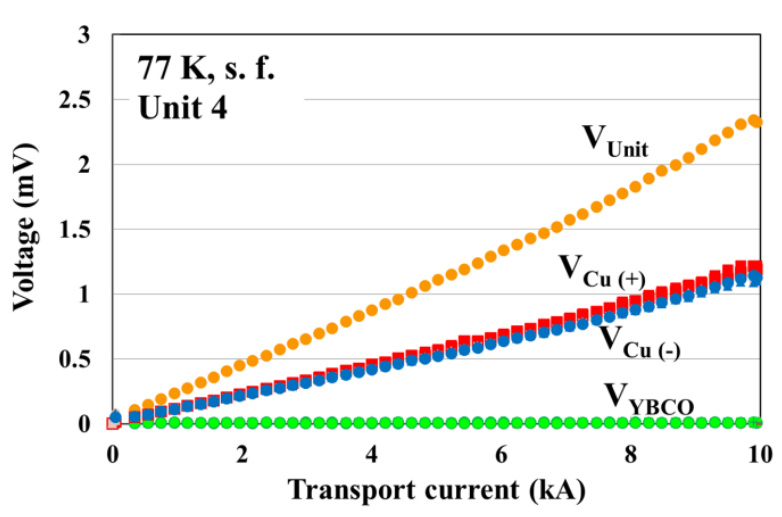

Fig. 6. Transport current performance of the current lead unit 4 (@77 K, s. f.).

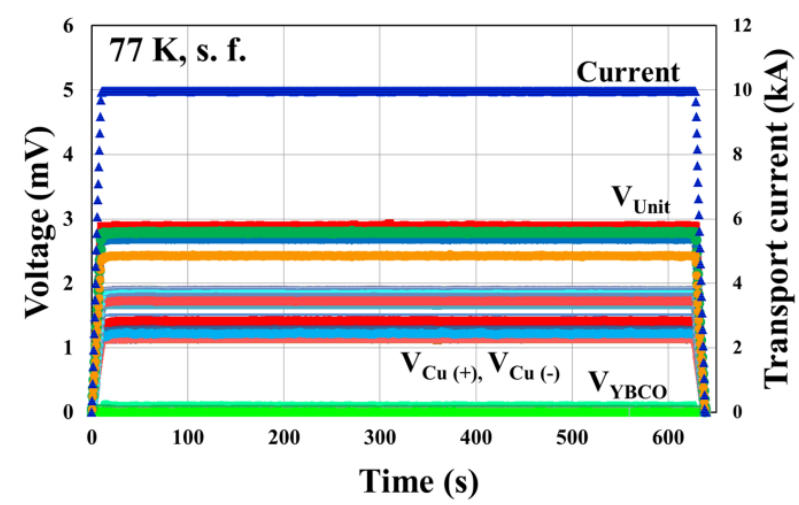

Fig. 7. Transport current performance of the assembled current lead (@77 K, s.f.).



Fig. 8. Voltage in Rogowski coil vs transport current up to $10 \mathrm{kA}$ at sweep rate of $2500 \mathrm{~A} / \mathrm{s}$. 


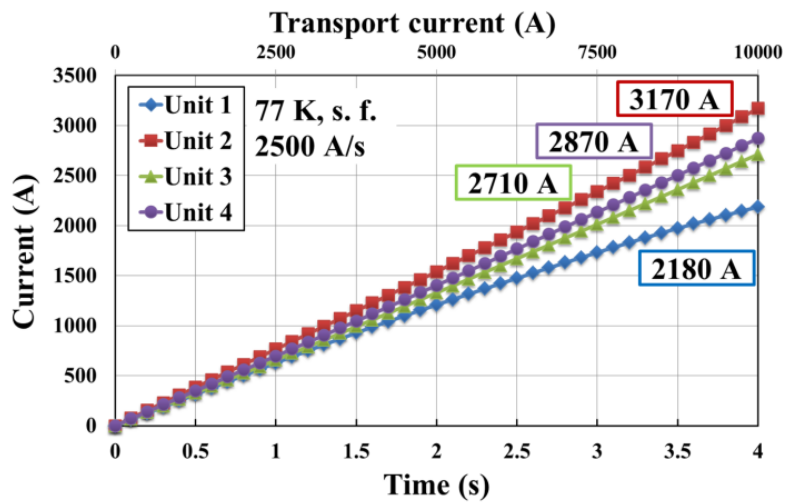

Fig. 9. Current distribution between 4 units in transport current of $10 \mathrm{kA}$.

\section{CONCLUSIONS}

1. TFA-MOD 法 YBCO 線材を 24 本使用した電流リー ドユニットを 4 組作製し、これらを集合させた 10 $\mathrm{kA}$ 級集合型電流リードを作製した。

2. 集合型電流リードは、液体窒素中・自己磁場下にお いて $10 \mathrm{kA}$ 通電時まで $\mathrm{V}_{\mathrm{Cu}(+)} 、 \mathrm{~V}_{\mathrm{Cu}(-)} 、 \mathrm{~V}_{\mathrm{Unit}}$ は直線的
に増加し、 $\mathrm{YYBCO}_{\mathrm{Y} O}$ に電圧が発生することなく通電で きた。また $10 \mathrm{kA}$ を 10 分間連続通電しても $\mathrm{V}_{\mathrm{Cu}(+)}$ 、

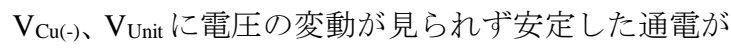
可能であった。

3. $2500 \mathrm{~A} / \mathrm{s}$ で $10 \mathrm{kA}$ 通電時における集合型電流リード 各ユニット間には、3170 A 2180 A の電流が流れた ものと計算され、最大で $990 \mathrm{~A}$ の偏流が生じたこと が推定された。各ユニットの電流值の和は $10930 \mathrm{~A}$ と計算され、実際の通電電流值である $10 \mathrm{kA}$ とは 930 A の差が生じたが、集合型電流リードの偏流をある 程度定量的に評価出来た。

\section{REFERENCES}

${ }^{1}$ H. Motohashi, Y. Sakai, Y. Hosono Y. Yamada, T. Koizumi, Y. Hikichi, M. Minowa, H. Tamura and T. Mito, Abstracts of CSSJ Conference, Vol. 86 (2012), p19.

2 Y. Hosono, H. Motohashi, R. Matsumura, Y. Yamada, Y. Hikichi, M. Minowa, T. Koizumi, H. Tamura and T. Mito, Abstracts of CSSJ Conference, Vol. 88 (2013), p146. 